\title{
Concepts and definitions for product recovery: analysis and clarification of the terminology used in academia and industry
}

\author{
Mattias Lindahl, Erik Sundin, Johan Östlin and Mats Björkman
}

Linköping University Post Print

\section{Tweet}

N.B.: When citing this work, cite the original article.

Original Publication:

Mattias Lindahl, Erik Sundin, Johan Östlin and Mats Björkman, Concepts and definitions for product recovery: analysis and clarification of the terminology used in academia and industry, 2006, Innovation in Life Cycle Engineering and Sustainable Development, 123-138. ISBN: 978-1-4020-4601-8 (online) 978-1-4020-4617-9 (print)

http://dx.doi.org/10.1007/1-4020-4617-0_8

From the $12^{\text {th }}$ CIRP International Conference on Life Cycle Engineering, Grenoble, France, April, 2006

Copyright: Springer

http://www.springer.com/ 


\title{
Concepts and definitions for product recovery - Analysis and clarification of the terminology used in academia and industry
}

\author{
M. LINDAHL ${ }^{1}$, E. SUNDIN ${ }^{2}$, J. ÖSTLIN² AND M. BJÖRKMAN ${ }^{2}$ \\ ${ }^{1}$ Division of Environmental Technology and Management, Department of Mechanical Engineering, Linköping \\ University, SE-581 83 Linköping, Sweden, ${ }^{2}$ Division of Production Systems, Department of Mechanical \\ Engineering, Linköping University, SE-581 83 Linköping, Sweden \\ Mattias.Lindahl@ikp.liu.se
}

\begin{abstract}
This paper presents and clarifies the academic and industrial terminology used in the area of product recovery. It is concluded that there exist many different concepts and definitions in academia and industry, several of which are unclearly defined. Given this, a new way to define product recovery is presented through the use of a model. This model is based on actual industrial product recovery cases, existing academic product recovery concepts and definitions and product design theory. The presentation contains a holistic model that can be used for describing and analyzing different product recovery scenarios. In addition, several industry cases are presented as a verification of the model.
\end{abstract}

Keywords:

Product Recovery, Remanufacturing and Refurbishment

\section{INTRODUCTION}

Product recovery has traditionally been viewed as an economically beneficial alternative to the ordering of new products. Product recovery is interpreted as a superior concept that involves concepts like reuse and recycling. The aim with product recovery is to retrieve a product's inherent value when the product no longer fulfills the user's desired needs. A product is in this context interpreted as an artifact produced to fulfill a user's desired needs. This also implies that material is interpreted as a product.

During the last century, the industrialized world has put limited focus on product recovery. Instead, the main focus has been on the production of products from virgin materials (i.e. non-recycled). For several different reasons, the focus has now shifted to product recovery. For example, countries like China with a large population and huge material needs are driving up material prices. In parallel, society's awareness of the environmental problems of the present use of material and products has grown [1]. Today, much of the raw materials and products in society are used only once, and instead of product recovery, new products and materials are produced. The new production of products as well as the treatment of used and unwanted products causes a lot of environmental problems.

As a result, the European Union (EU) has issued several directives to change the rate of material and product utilization in order to reduce its environmental impact [2]. Examples are Waste Electronic and Electrical Equipment (WEEE) [3], Restricting the use of Hazardous Substances (RoHS) [4], Integrated Product Policy (IPP) [5] and several producer responsibility directives, e.g. on vehicles [6].

For example, WEEE aims primarily to prevent the accumulation of waste containing electrical and electronic products, and at the same time promote reuse and material recycling of these kinds of products. According to this directive, the members of the European Union shall encourage design and manufacturing of electrical and electronic products that facilitates dismantling and recycling, especially reuse and recycling of components and materials from these products. [3]
Furthermore, the EU has developed an Integrated Product Policy (IPP) that aims at reducing the usage of material and the environmental impact of waste [5].

Product recovery is breaking through into new industry sectors, e.g. because of increased material costs. Some industry sectors - for example the automotive industry have extensive experience in this area when compared to other expanding sectors such as personal computers and cellular phones. The different industry sectors have developed their own, and not standardized expressions and terminology for their business within the product recovery area. They refer to themselves, for example, as "remanufactures", "rebuilders", "retreaders", "rechargers", "refurbishers", and "reconditioners" [7].

The vast number of terms within the product recovery area is a source of confusion within and between both industry and academia. Because of this, researchers and industrial practitioners could mean the same thing but name it differently, or alternatively use the same concepts but interpret them differently. The increasing number of companies entering the product recovery business, combined with the expanding research in this area, highlights the need for a holistic mapping of terminology in this area. Such a mapping, it is envisioned, could help clarify and describe the existing relationships between different academic and industrial concepts, and could facilitate both academic and industrial communication and collaboration.

\section{AIM}

The first aim of this paper is to identify and clarify the terminology for product recovery scenarios used by academia and industry. The second aim is to describe a holistic model for researchers to map different industrial product recovery systems in order to facilitate research in this area, e.g. communication and comparisons of different product recovery systems. The model describes different types of product recovery. The basis for this model is the existing experience found within both industry and academia, i.e. real industrial cases and existing concepts and definitions. 


\section{METHODOLOGY}

The methodology for conducting this research was to study research within the area of product recovery, as well as the industry of product recovery itself. In regards to the theoretical study presented in this paper, a number of popular theories in academia were compared and analyzed.

Furthermore, the industrial cases of Swedish product recovery presented here highlight the use of several concepts. These case studies were conducted through Internet surveys and telephone interviews. Finally, several industrial cases were utilized to help verify the authors' proposed model for product recovery, of which some, but not all, are presented in this paper.

\section{RESEARCH DEFINITIONS}

Products can be recovered in many ways, and this recovery can be performed at different levels. For example, at a lower level, it could be the product materials that are recovered. In this case, it is often called "material recycling". Product recovery on a higher level, where product parts or modules are reused, is often called "remanufacturing", "reconditioning" or "refurbishment". A remanufactured product is often the term used to describe a worn-out/broken/used product that has been restored to its original specifications or has been modernized and upgraded to new specifications. Hence, remanufacturing not only promotes the multiple reuse of materials, but it also allows for the steady upgrading of product quality and functionality, and does this without the need to manufacture completely new products and scrap used ones [8].

It is important to avoid confusion in terminology, for example between reuse and recycling, as the environmental impact of reuse will usually be much less than recycling [9]. Recycling involves reprocessing products or components into basic material, which are subsequently used as input in new manufacturing. According to one observer, "the confusion is arising because industry is keen to suppress the idea of re-use, whilst the environmental movement has failed to promote it" [10]. In other words, industry is acting on an assumption that recycling and subsequent manufacturing will be more profitable than re-use, while campaigners have not been effective enough in promoting re-use.

There exist many definitions for product recovery. The following definitions of reuse, remanufacturing, reconditioning, refurbishment, component cannibalization and material recycling illustrate the complexity of describing the product recovery area:

\section{Reuse is...}

...the process of disassembling products to recover useable parts and assemblies for the purpose of utilizing them in newly manufactured products [11].

...the additional use of a component, part or product after it has been removed from a clearly defined service cycle [12].

\section{Remanufacturing is ...}

... an industrial process in which worn-out products are restored to like-new condition. Through a series of industrial processes in a factory environment, a discarded product is completely disassembled. Usable parts are cleaned, refurbished, and put into inventory. Then the new product is reassembled from both old and, where necessary, new parts to produce a unit fully equivalent and sometimes superior - in performance and expected lifetime to the original new product [13].
... when a product is cleaned and repaired to return it to a 'like new' state; often requires completely disassembling the product. [14]

... the process of rebuilding a product. During this process the product is disassembled, defective components are replaced and the product is reassembled, tested and inspected to ensure it meets newly manufactured product standards [11].

... an industrial process whereby products are restored to like-new condition. In contrast, a repaired or rebuilt product normally retains its identity, and only those parts that have failed or are badly worn are replaced or serviced [15].

... the most economically sustainable form of reuse and recycling of manufactured goods, and it can be defined as the industrial process where worn out products, referred to as cores, are brought back to original specifications and condition [16].

... the practice of disassembling, cleaning, refurbishing, replacing parts and reassembling a product in such a manner that the part is at least as good as, or better than, new. By remanufacturing a product, the product may be returned to service with a reasonably high degree of confidence that it will endure (at least) another full lifecycle [17].

... an industrial process whereby products referred as cores are restored to useful life. During this process the core passes through a number of remanufacturing steps, e.g. inspection, disassembly, cleaning, part replacement/ refurbishment, reassembly, and testing to ensure it meets the desired product standards [8].

\section{Reconditioning is ...}

... the process of restoring components to a functional and/or satisfactory state but not above original specification using such methods as resurfacing, repainting, sleeving, etc. [16].

\section{Refurbishment is ...}

... the process in which a product or component is cleaned and repaired in order to make a resell [18].

... when a product is cleaned and repaired to return it to a 'like new' state [14]

\section{Component cannibalization is ...}

... the process in which a limited number of components are extracted from a product for recovery [18].

... when parts or components are taken off of one item and used to repair or rebuild another unit of the same product. [14]

\section{Material recycling is ...}

$\ldots$ the process by which materials otherwise destined for disposal are collected, processed, and remanufactured into new products. Composting is a form of recycling [19].

... the process in which the structure of a product is destroyed in order to recapture its materials [18].

... when a product is reduced to its basic elements, which are reused [14].

... the series of activities, including collection, separation, processing, by which products or other materials are recovered from or otherwise diverted from the solid waste stream for use in the form of raw materials in the manufacture of new products other than fuel [12].

\subsection{Summary of Research Definitions}

As previously stated in the introduction, one of the major problems for understanding and communication in the area of product recovery are the numerous definitions in use for the same concept. Furthermore, there are also many similar concepts describing more or less the same thing. 


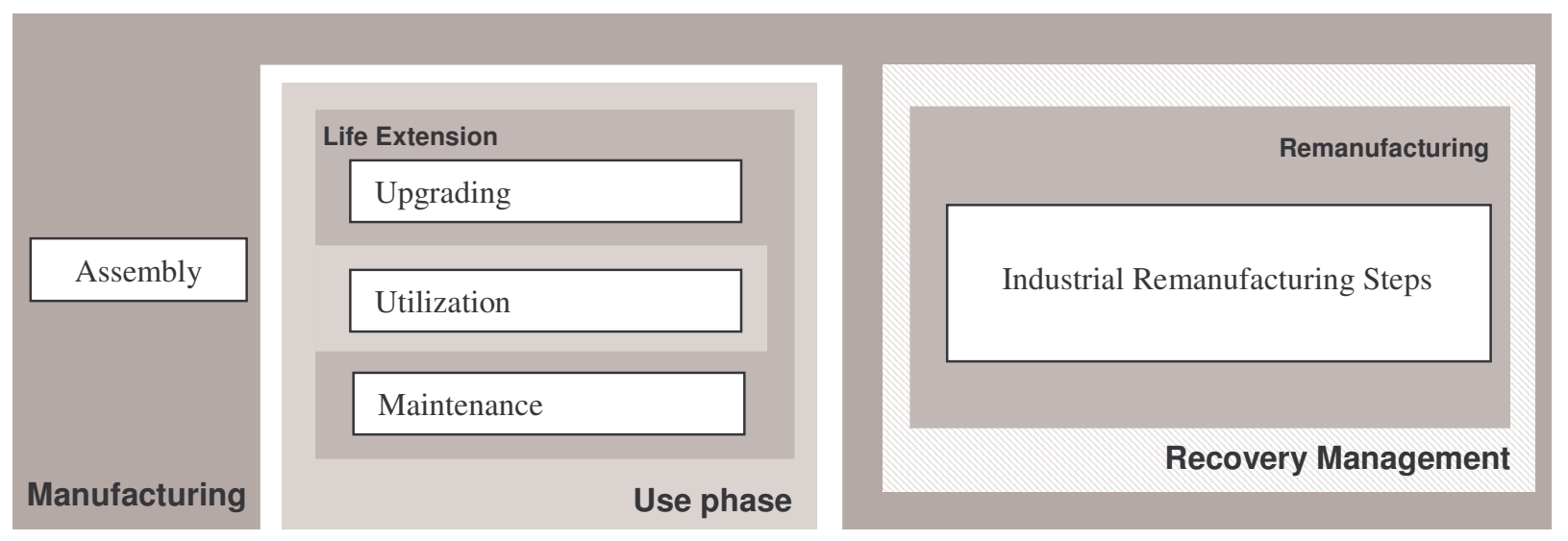

Figure 1: Mapping of different concepts and their relationships

Table 1. Relationship between several concepts used in the model and those used in academia and industry.

\begin{tabular}{|l|l|}
\hline Model concepts & Alternative academic and industrial concepts \\
\hline Function provider & Product, Core \\
\hline Sub function provider & Product, Part, Spare part, Component, Core, Module \\
\hline Manufacturing & Production \\
\hline Recovery management & Closed-loop supply chain, Reversed logistics \\
\hline Remanufacturing & Refurbishment, Reprocessing, Reconditioning \\
\hline
\end{tabular}

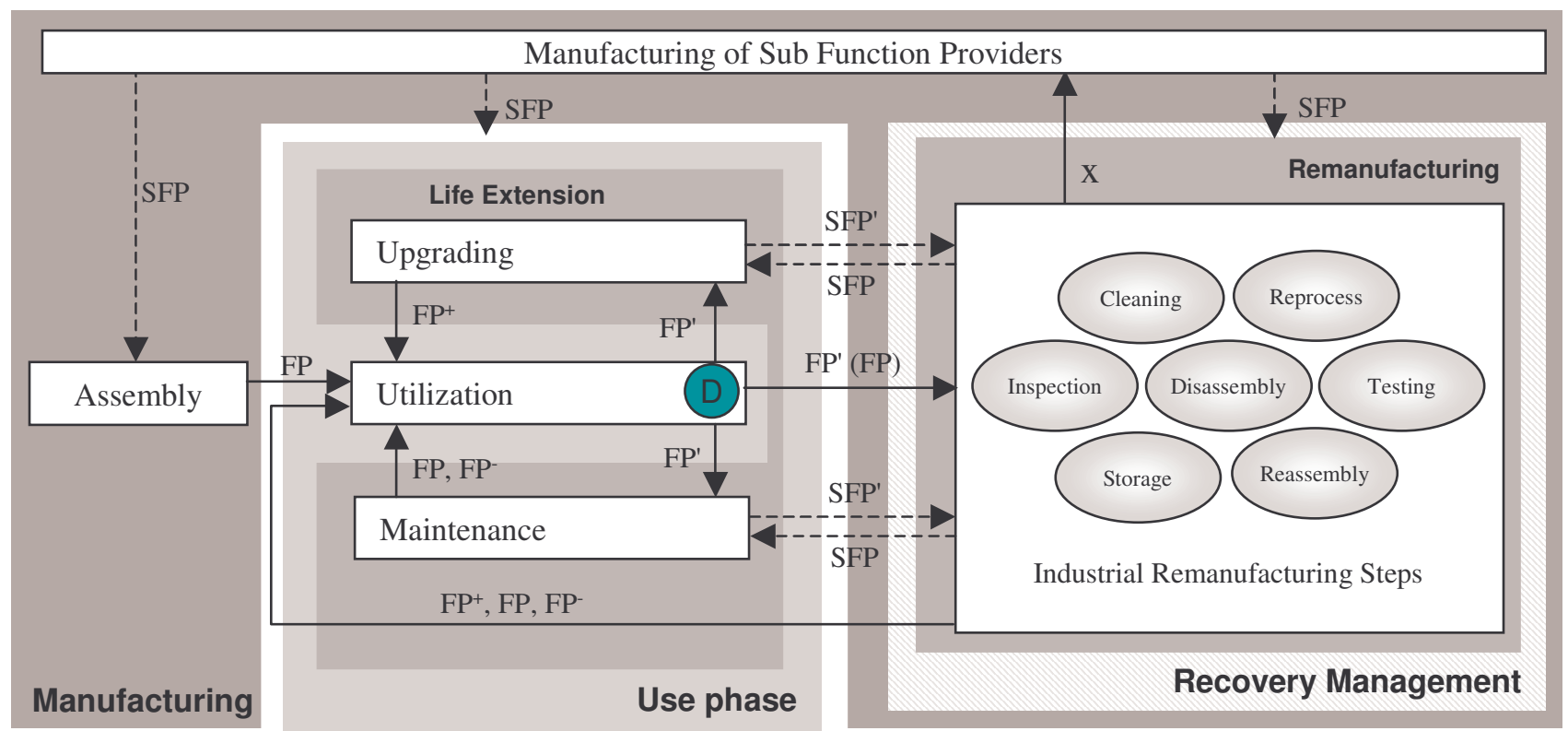

Figure 2: Generic Life Cycle of Function Providers, with the abbreviations Function Provider (FP) and Sub Function Provider (SFP), where X represents one or more FP's or SFP's that are transformed into SFPs (One example of this is material recycling, where the $X$ then represents the FP's or SFP's that are treated by "Sub Function Provider Manufacturing" e.g. at a refinery or recovery factory)

Some of these different concepts are used by industry to define the quality level of the product being recovered. This is the case, for example, for the definitions of reconditioning and refurbishment.

Reconditioning/refurbishing is often used when the product is only restored to its original specifications [20]. Remanufacturing, in any event, is becoming the generic term for the process of restoring discarded products to useful life [7]. If the rebuilding of the product is not extensive, i.e., if few parts are to be replaced, either of the terms reconditioning or refurbishing is commonly used by industry [8].

Another and related obstacle is that several of the existing definitions use general and unclearly defined concepts, making these concepts tricky to use due to the fact that different users may interpret them differently. An example of this is the confusion resulting from the ambiguity of the terms "product" and "components" (see Table 1). 


\section{INDUSTRIAL CASES}

In the product recovery process, as we have seen, the condition of the returning cores can be in different states and thus suitable for different product recovery options. It is important to note that there is a gap between the terminology used in academia and that used in practice. To illustrate some of the problems associated with this gap, several of the industrial cases investigated for this paper are presented here.

\subsection{Computer Case}

This case considers a process where faulty computers, monitors and other equipment undergo a recovery process. The condition of the computers is determined through an inspection, using specific software which can identify malfunctioning components that have to be replaced. Through the use of various software applications a reprocessing activity is created, whereby the memory of the computer is erased and then brought back into operation. The computer is then sold to a new customer, thereby entering another use phase. The company uses the term "refurbishment" to describe this process. Another company which primarily deals with warranty claims for OEMs and broken equipment uses a similar process. In this case, items are tested, and if possible, parts are replaced or repaired. The repaired items are then sent back to the same customer to be used again. This process is referred to as "reparation", and the product is repaired. There is, however, and important difference in these two cases: in the first, the computer is sold to a new customer; in the second, the computer remains with the original user. This implies that the remanufacturing company's relationship to the user is an important aspect for the terminology used to describe the product recovery process.

\subsection{Engine Case}

Here we consider a process with two different outputs: one that meets or exceeds the level found in new production, and one that is in line with customer demands. In the first case, the item is completely investigated and all of the parts that not are in a "like new" condition are replaced. The items are then reassembled and tested, and the resulting item is referred to as "remanufactured". To create an option for the cost sensitive customer, another method is used. In this process, all of the parts are still inspected, but only those not meeting customer demands are replaced, meaning even parts that do not qualify as "like new" can be used once more. The resulting item from this process is referred to as "functional repaired". These processes are more or less the same, but the resulting product quality levels are different. This implies that the type of recovery process has no direct influence on the term used to describe these types of recovery processes.

\subsection{Heat Exchanger Case}

In another case of product recovery for plate heat exchangers, the plates are disassembled and thereafter cleaned and reprocessed. After reassembly, the heat exchangers are tested. According to the company, this process produces products which are essentially as good as new, although the terminology used by the company to describe these products is "refurbished". This shows that the quality of the product can be referred to with different terminology depending on the industry sector.

\subsection{Toner Cartridge Case}

A laser printer consists of many levels of sub assemblies and different parts; one of them is the toner cartridge. When the toner level in the printer runs low, a need for refilling arises, and the empty cartridge must be removed from the printer and sent for product recovery activities.
First the cartridge is inspected to determine which of the parts can be replaced or repaired. Then the cartridge is reassembled, refilled and tested, exiting the process as a "good as new" product. The cartridge can continue its new use phase in the same printer or in a different one. This case illustrates how sub functions in a product that are considered to be maintained/repaired can undergo a recovery process. It also shows that, depending on which of the functions go through recovery, how different terminology is used.

\section{FUNCTION PROVIDERS}

According to existing theory about product design, described by for example Roozenburg and Eekels [21], the presumptive user is interested in benefits the product may provide in fulfilling various kinds of needs. This could be, for example, a product's means to provide desired functions. A product is, according to Roozenburg and Eekels [21], a material system which is made by people for its properties. Because of these properties, it can fulfill one or more functions. By fulfilling functions a product satisfies needs, thereby giving users the possibility to realize one or more values. In some cases, the customer and the user are one in the same, but this is not a necessity.

In accordance with the theory concerning product design, manufacturing companies tend to strive to fulfill users' needs by producing artifacts with a desired function. This is also in line with the terminology used to describe product recovery in this paper. Thus, instead of focusing on the recovery of "products" or "components" or "materials", the focus is put on the "functions" which manufacturers produce to satisfy their customers' needs. This implies that a product can be interpreted as a function provider (FP). Depending on the perspective and focus, a product or a component can be interpreted as a combination of products and components, in the same manner a FP can be seen as a combination of sub function providers (SFPs).

\section{THE GENERIC LIFE CYCLE OF FUNCTION PROVIDERS}

The mapping in Figure 1 presents some of the more used concepts relations to each other. Based on this, Figure 2 was developed to describe a generic model for describing different FP concepts life cycles. Before the model in Figure 2 is further described, however, some concepts used in the model are described.

\subsection{Definitions of Concepts Used in the Model}

All concepts used in the proposed model have been collected from the existing theory in order to avoid introducing yet more concepts that could cause more confusion. However, the different concepts' definitions have been transformed and translated in the respect that they are related to various kinds of FPs instead of, e.g. products, parts and components. Table 1 shows the relationship between some of the model's concepts and those used in academia and industry.

Function provider (FP) is defined as "an artifact with a specific function that is provided by a combination of sub function providers, aimed to fulfill a customer's desired need". The FP's functions can be described and defined and must more or less fulfill and correspond to the customer's need; otherwise, the FP will most likely be rejected.

Sub function provider (SFP) is defined as "a subordinated FP that is used in a FP". An example of a SFP could be the toner cartridges for a laser printer. If the major focus is on the printer, then the printer becomes the FP and the cartridge the SFP. However, if the major focus 
is on the toner cartridge, then the toner cartridge is the FP and e.g. the toner material the SFP.

Manufacturing is defined as "an organized process to manage, assemble and develop FPs".

Assembly is defined as "an organized process to put together different SFPs into a FP, with a defined function that is aimed at fulfilling a customer's desired need".

Use phase is defined as "the time from the FP delivery to the customer until the FP no longer can fulfill the desired customer's needs".

Life extension is defined as "processes that extend a FP's use phase".

Utilization is "the phase when the FP is generating the benefits that fulfill the customer's desired needs". An example of utilization is the time the car is in actual use, i.e. is transporting the passenger in order to fulfill the desired need of transportation. The utilization phase can involve several different customers. During the utilization there may exist a consumption of SFPs needed to receive the benefits. Examples of consumed SFPs are gasoline, detergents and toner.

Maintenance is defined as "a process to preserve the FP's specific function". This may involve steps such as cleaning, inspection, disassembly, testing, storage, reassembly and repair. Examples include performing inspections to foresee and prevent malfunctions, or checking oil pressure and repairing malfunctioning SFPs, such as spark plugs and batteries.

Upgrading is "a process when the FP's specific function is improved by adding, for example, better and more advanced SFPs". This may involve steps like cleaning, inspection, disassembly, testing, storage and reassembly. The result is an upgraded FP in comparison with the original. An example can be a computer (FP) that is upgraded with a new processor (SFP).

Recovery Management "encompasses the management and industrial process that set out to retrieve the intrinsic value of a FP".

Remanufacturing is defined as "an organized process to retrieve a FP's intrinsic value by combining and reorganizing different FPs into a new FP that corresponds towards a consumer's desired needs". This process can be divided into several process steps, which Sundin [8] refers to as the Generic Remanufacturing Process.

\subsection{Principal Description of the Model}

The continuous lines in the model shown in Figure 2 illustrate the flow of FPs, while the dashed lines illustrate the flow of various SFPs needed to accomplish the different processes during a product's lifecycle.

Before using the model, there is a need to decide the focus for the description, i.e. the FP. Is it, for example, a forklift truck or a forklift truck's engine? In the first alternative, the forklift truck is the FP and the engine is the SFP, and it is this case which will be used as an example in the following description. The forklift truck (FP) is assembled from many SFPs; the engine is but one example. During the utilization phase (which can involve many different owners as well as users) there is consumption of different SFPs, e.g. fuel, to receive the function. Later during utilization, either the FP's SFPs lose their ability to provide the specific function (e.g. the engine malfunctions) or customer needs are altered in such a manner that the FP no longer fulfills their desired needs ${ }^{1}$. An example of the later is when the lifting capacity is too small compared to the required capacity. The result is a degraded FP labeled FP'.

\footnotetext{
${ }^{1}$ This is not valid for demo products.
}

The degraded FP can be treated in three different ways depending on the customer's decision taken at point $D$. The first two ways are life extension within the use phase, while the third is recovery management, implying that the FP leaves the present use phase.

In the first alternative, the customer decides to upgrade the $\mathrm{FP}$ to a $\mathrm{FP}^{+}$. $\mathrm{FP}^{+}$represents a $\mathrm{FP}^{\prime}$ that has been transformed into a new FP with, when compared to the original FP, higher functionality. The customer is in charge of the upgrading, and decides what to do with the FP. The upgrading process may involve several of the industrial remanufacturing process steps, and may imply that some SFP are replaced with new ones. It may also imply that certain SFP's (e.g. the engine) are sent away for remanufacturing at a remanufacturing company to upgrade the SFP (e.g. increase the power) and then sent back (note the dashed lines in Figure 2).

The second alternative is that the customer decides to maintain the functionality ${ }^{2}$ (FP) or want a lower level (FP') than the original functionality. This alternative is valid for ordinary performed maintenance. In accordance with upgrading, this may imply that some SFPs are replaced and that some are sent for remanufacturing and then sent back (see dashed lines in Figure 2).

The third alterative is that the customer decides to reject the FP'. This alternatives differs from the two above in that the responsibility for the $\mathrm{FP}^{\prime}$ is handed over to a manufacturer, usually a remanufacturing company. It is then up to the remanufacturing company too decide, depending on the status etc., what to do with the FP'. The results may be, for example, a $\mathrm{FP}^{+}$, a $\mathrm{FP}$ or a $\mathrm{FP}^{-}$that are sent back for a new use phase, but it may also a X. Xs represents either one or many FP's or SFP's that are transformed to SFPs - SFPs that are used in other types of FPs. This implies e.g. that the fork lift trucks' engines are used for powering a pump station and that other SFPs are used in newer, more modern fork lift trucks. Important to note is that the resulting FP may be bought back by the original customer.

\section{INDUSTRY CASE EXAMPLES}

As an example of how the model works, some of the cases presented earlier are described using this model. The model has been evaluated with more than 20 industrial cases; however, only three of those cases are presented in this paper.

\subsection{Computers Case}

Consider a computer (FP) not satisfying a customer's need; in this scenario, the function must be restored. There are several options: an upgrade can be made on the product, the product can be sold as it is to a different customer, the product can be resold or delivered to a remanufacturer for further use in the next use phase, or it can be sent to material recovery for scrapping.

For the upgrading of a computer, sub functions (SFPs) such as the CPU are replaced with other SFPs, and sent for recovery for their material value (1).

When the product leaves the use phase and enters the recovery process, various actions take place depending on the aim of the recovery option. Different quality levels of computers exit the remanufacturing process and enter the next use phase (2). Some materials and cannibalized parts exit the process as SFPs, and can be used in other functions.

${ }^{2}$ Functionality is defined as "the combination of functions and their behavior that contribute to making the FP useful for an intended purpose." 


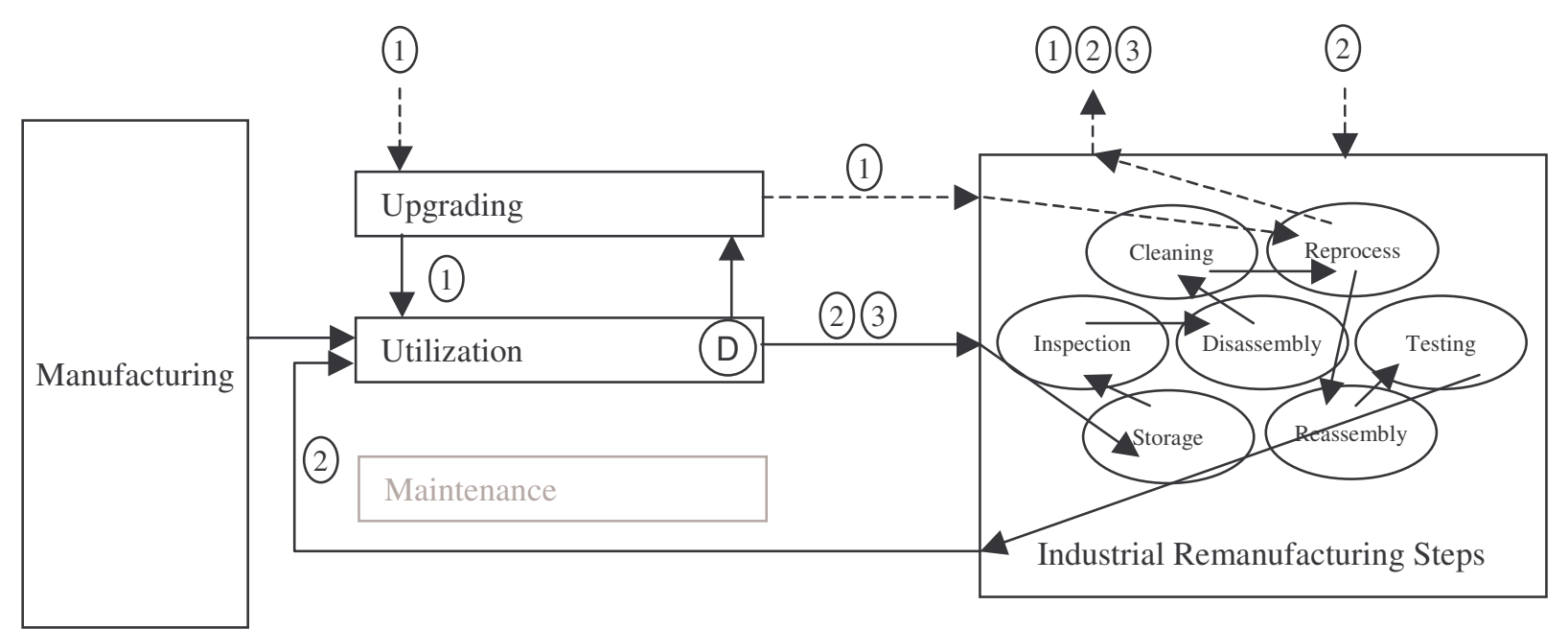

Figure 3. Computer case $(\mathrm{FP}=\mathrm{A}$ Computer $)$

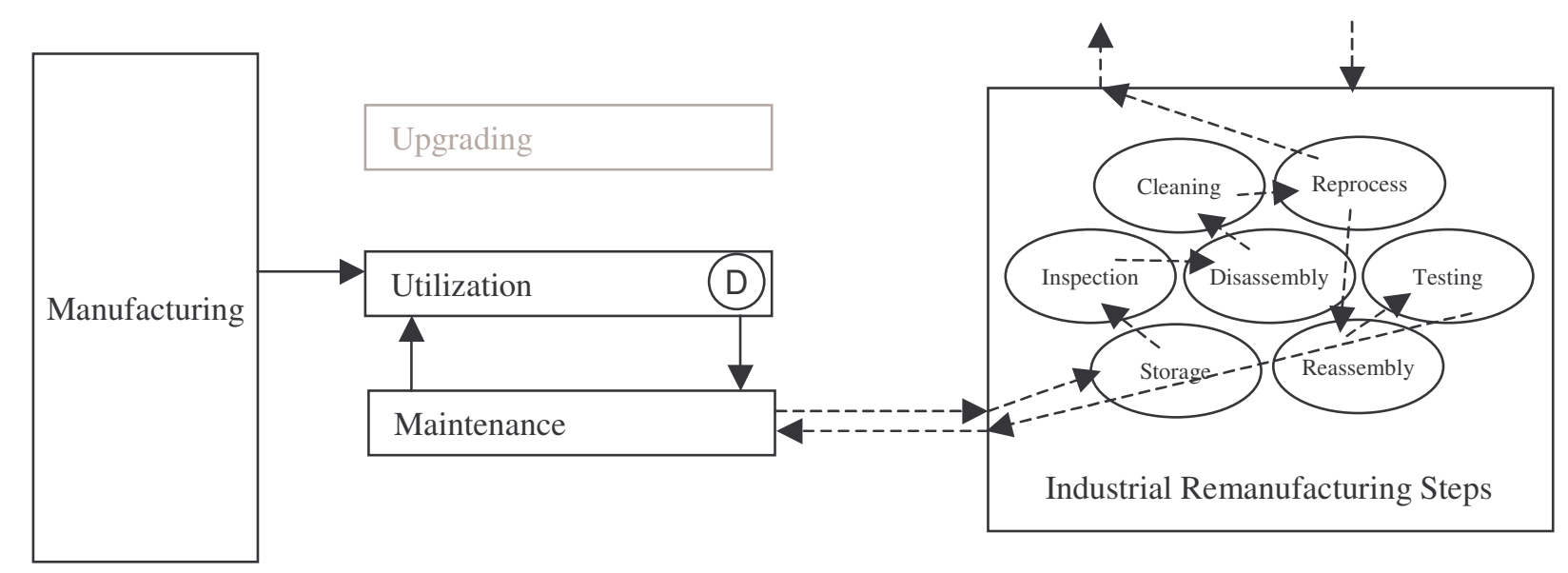

Figure 4. Printer case $(\mathrm{FP}=\mathrm{A}$ Printer $)$

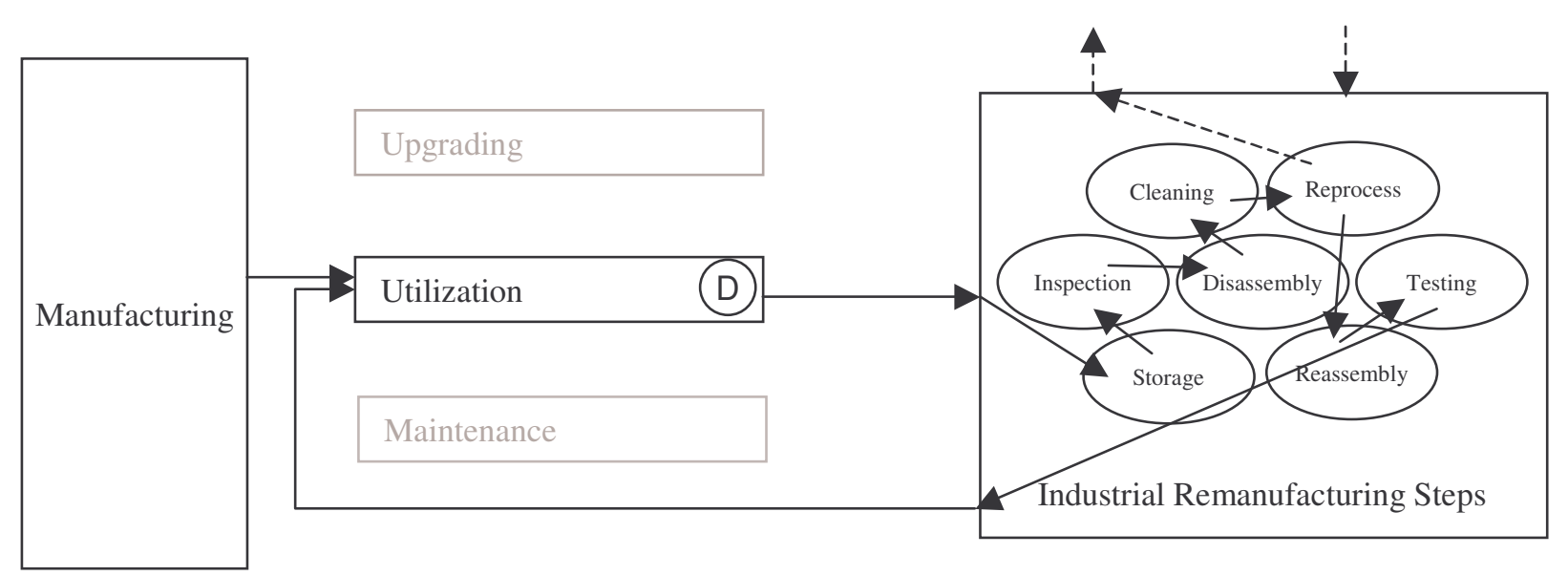

Figure 5. Toner cartridge case (FP $=$ A Toner Cartridge) 


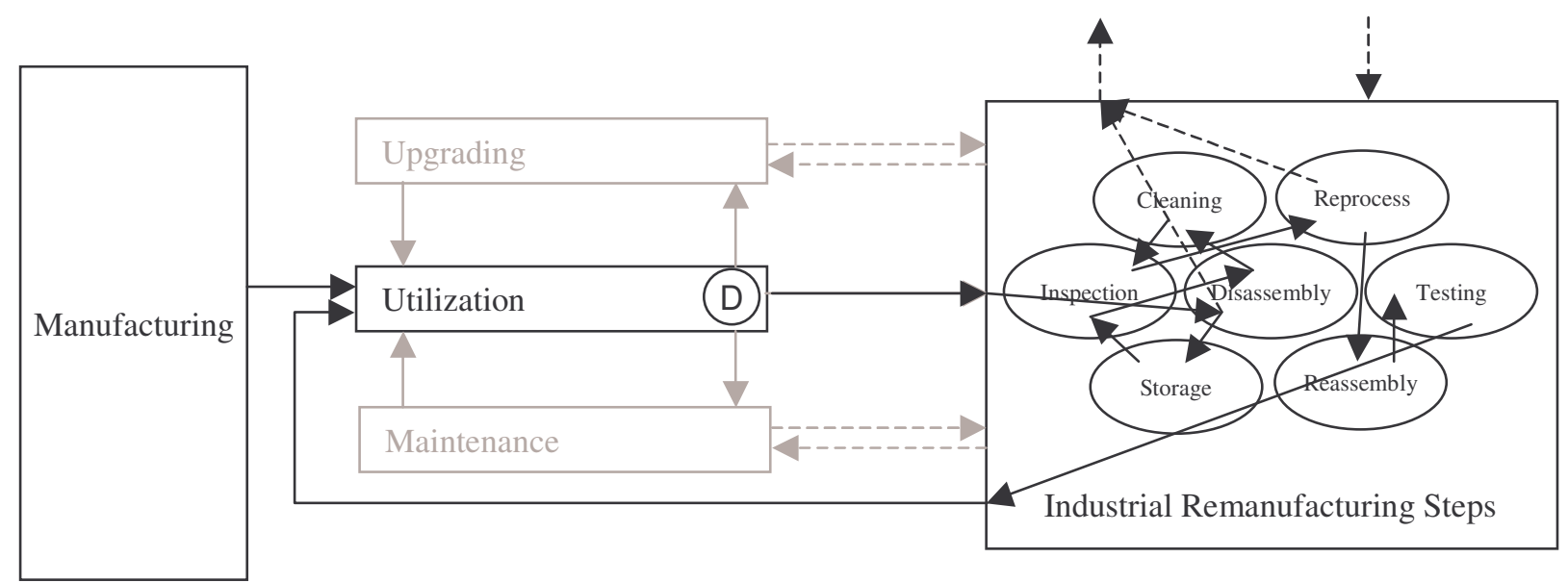

Figure 6. The Single Use Camera Case (FP = A Single Use Camera)

The FP can also be material recovered (3). For an illustration of the options 1-3 applied on the model, see Figure 3.

\subsection{Printer and Toner Cartridge Case}

The cases of the printer and the toner cartridge are illustrated in Figures 4 and 5 . In the first case, the printer is considered as the FP, as seen in Figure 4. The toner (SFP) in the toner cartridge (SFP) is consumed during the utilization. When a toner cartridge runs empty, a replacement of the cartridge is needed to ensure the printer's (FP's) functionality. The printer usually newer change it is physical location during this process. A new toner cartridge (SFP) is asembled into the printer and the empty toner cartridge is sent for a remanufacturing process and undergoes different steps that are further described in the next paragraph. The remanufactured toner cartridge is then either returned to the same printer or a similar printer.

In the second case, the toner cartridge is considered to be the FP, as shown in Figure 5. When the toner, in this case considered to be a SFP, is consumed, the toner cartridge loses its functionality and must be remanufactured. The toner cartridge is first sent to a remanufacturer, where it is stored until inspection of the cartridge. Next, an appropriate recovery option is chosen. Disassembly, cleaning and reprocessing of the items in the cartridge is carried out, some items are material recycled, and others are cannibalized to be used elsewhere. Following this, the items that exit the process are then replaced by various SFPs. In the next step, the cartridges are refilled with toner and then tested to ensure functionality before returning to the new use phase.

\subsection{The Single-Use Camera Case}

The case of the single-use camera case is presented in Figure 6. Consider a camera (the FP) with which a customer has taken all available pictures on the camera film (SFP). The customer then returns the single-use camera to a photo shop, where the film is removed and the camera put in storage awaiting shipment back to the OEM. At the OEM, the single-use cameras follow the sequence of sorting (inspection of shape), disassembly, cleaning, inspection, repair, reassembly and inspection. In the reassembly step, new film is added. The reassembled single-use camera is then returned to a photo shop, and a new use phase begins.

\section{DISCUSSIONS AND CONCLUSIONS}

This paper illustrates through a number of both academic and industrial examples the conflicts between several of the existing concepts and definitions used in area of product recovery. Furthermore, it is concluded that several of the concepts are inappropriately defined. One problem is the use within the definitions of general concepts where "product" and "component" are two such examples. These concepts are widespread, but the interpreted meaning differs depending on the interpreter's context and focus. For example, what may be considered for one person to be a product, e.g. a toner cartridge, might be viewed by another as a component in a printer. This may result in misunderstandings and confusion in the dialogue between researchers and in the analysis of different product recovery scenarios.

Furthermore, some of the concepts, e.g. refurbishing, represents a degree of remanufacturing. At the same time, the definitions and borders between the different degree concepts are vague and unspecified.

One advantage with the proposed idea and concept of function providers is that the focus is on the function, the inherent value of the artifact. To describe the different used function providers facilitate the analysis and understanding of for example a product recovery system. The proposed concept also implies that there is no need to use an abundance of different concepts, e.g. product, part and component, to define the needed concepts, e.g. remanufacturing. In fact, the only needed concept is function provider and, as defined, the sub function provider is just a lower degree of function provider - but still a function provider.

A major contribution of this paper is the holistic model with its related concepts and definitions. As described, this model can be used in order to describe and analyze different companies' products and product recovery concepts.

The conclusion is that the function provider concept and the holistic model provide a more general and consistent way to describe product recovery scenarios. This, in relation to the existing terminology and models that have been found in academia and industry. Hopefully this holistic model will represent a starting point for continued work towards more harmonized and standardized terminology that would be beneficial for the product recovery area. 


\section{ACKNOWLEGEMENT}

This research has been conducted within the project "Sustainable systems and products for reuse and remanufacturing". This project is funded by VINNOVA, The Swedish Agency for Innovation Systems. We give a special thanks to Professor Yoshiki Shimomura and Doctor Tomohiko Sakao at Research into Artifacts, Center for Engineering (RACE). The University of Tokyo, Japan for fruitful discussion and co-operation.

\section{REFERENCES}

[1] Ryding, S.-O., Miljöanpassad produktutveckling. 1995, Stockholm, Sweden: Industrilitteratur AB.

[2] Tukker, A., E. Haag, and P. Eder, Eco-design: European state of the art - Part I: Comparative Analysis and Conclusions - An ESTO project report. 2000A, European Commission - Joint Research Centre Institute for Prospective Technological Studies: Brussels, Luxembourg. p. 60.

[3] EU, Directive 2002/96/EC of the European Parliament and the Council of 27 January 2003 on waste electrical and electronic equipment (WEEE). Official Journal of the European Union, 2003.

[4] EU, Directive 2002/95/EC of the European Parliament and or the Council of 27 January 2003 on the restriction of the use of certain hazardous substances in electrical and electronic equipment. Official Journal of the European Union, 2003.

[5] EU, Integrated Product Policy - Building on Environmental Life-Cycle Thinking. 2003, Commission of the European Communities: Brussels. p. 30.

[6] EU, Directive 2000/53/EC of the European Parliament and of the Council of 18 September 2000 on end-of life vehicles. Official Journal of the European Communities, 2000(L269): p. 34-42.

[7] Lund, R., The remanufacturing Industry: Hidden Giant. 1996, Boston, Massachusetts: Boston University.

[8] Sundin, E., Product and Process Design for Successful Remanufacturing, in Production Systems, Department of Mechanical Engineering. 2004, Linköping University: Linköping, Sweden.

[9] Cooper, T., Beyond recycling: the longer life option. 1994, London, UK: New Economics Foundation.

[10] Fairlie, S., Long distance, short life: Why big business favours recycling. The Ecologist, 1992. Vol. 22 (No. $6)$.

[11] Seaver, W.B. Design Considerations for remanufacturability, recyclability and reusability and reusability of user interface modules. in Proceedings of IEEE International Symposium on Electronics and the Environment (IEEE-94). 1994. San Francisco, CA, USA

[12] Keoleian, G. and D. Menerey, Life Cycle Design Guidance Manual - Environmental Requirements and The Product System. 1993, United States Environmental Protection Agency.

[13] Lund, R.T., Remanufacturing Technology Review. 1983: p. 19-29.
[14] Rogers, D. and R.S. Tibben-Lembke, Going backwards: Reverse logistics trend and practices. 1998.

[15] APICS, APICS Dictionary. 9th Edition ed. 1998, Falls Church, VA, USA: APICS - The Educational Society for Resource Management. p. 81.

[16] Amezquita, T. and B. Bras. Lean remanufacturing of an Automobile clutch. in Proceedings of First International Working Seminar on Reuse. 1996. Eindhoven, The Netherlands.

[17] Bras, B. and R. Hammond. Design for Remanufacturing metrics. in Proceedings of First International Seminar on Reuse. 1996. Eindhoven, The Netherlands.

[18] REVLOG - The European Working Group on Reverse Logistics. 1999.

[19] Kopicky, R., Reuse and Recycling-Reverse logistics opportunities. 1983, Council of Logistics Management.

[20] ljomah, W.L., J.P. Bennet, and J. Pearce. Remanufacturing: Evidence of Environmentally Conscious Business Practice in the UK. in Proceedings of IEEE International Symposium on Electronics and the Environment (IEEE-99). 1999. Danvers, USA.

[21] Roozenburg, N.F.M. and J. Eekels, Product Design: Fundamentals and Methods. 1995, West Sussex, UK: John Wiley \& Sons, Ltd. 